\title{
PERSPECTIVAS DA AÇÃO TUTORIAL NO ESPAÇO EDUCATIVO NA ERA CONTEMPORÂNEA
}

\author{
Maria Clotildes Felix Gabry ${ }^{1}$ \\ Magda Schmidt Brasil ${ }^{2}$ \\ José Ferreira de Oliveira ${ }^{3}$
}

RESUMO: A intencionalidade deste artigo é abarcar nos caminhos e nas inúmeras possibilidades da ação tutorial nas diferentes etapas da educação básica, e no percurso acadêmico do estudante, contribuindo para o desempenho de crianças, jovens e adultos tomando como base a figura do tutor e os agentes que participam da ação tutorial na Era Contemporânea, tendo em vista as tecnologias digitais e os diferentes tipos de intervenções na sala de aula. Nossa pesquisa perpassa pela diversidade, momento pandêmico,e as tecnologias como aliada ao processo educativo, destacando. o perfil necessário para a atuação do professor tutor na garantia de novos saberes. Para o desenvolvimento integral do estudante, na construção da cidadania e no desenvolvimento pleno de ações integradoras.

Palavra-Chave: Ação Tutorial. Família. Formação Integral. Estudantes.

\section{INTRODUÇÃO}

Mediante a importância da ação tutorial dentro da sala de aula, circundaremos por diferentes níveis para enfatizarmos que o agir do tutor dentro das diversidades existentes na comunidade escolar contribuindo para a organização, do trabalho em grupo ou em pares permitindo um melhor conhecimento dos docentes com os estudantes, contribuindo com o

\footnotetext{
I Graduada em Pedagogia pela UNESC-RO, Pós-graduação em Alfabetização pela Universidade Federal de RO. Mestranda em Educação pela FUNIBER-UNEATLANTICO /Espanha Atua na SEDUC-RO, Coordenadoria Regional de Rolim de Moura, na Coordenação dos Anos Iniciais e Finais. Coordenou PNAIC e atualmente Tempo de Aprender. E-mail: gabryclotildes@gmail.com.

2 Graduada em Pedagogia pela ULBRA, Pós-Graduada em Neuropsicopedagogia clínica, Mestranda em TICs na Educação. Já atuou como professora de rede privada e como supervisora pedagógica na rede pública da cidade de Esteio no RS. E-mail: magda.brasil@gmail.com.

3 Graduado em Enfermagem pela UNICSUL - Universidade Cruzeiro do Sul - SP. Especialista em Enfermagem Obstétrica pela Faculdade Santa Marcelina. Especialista em Assistência de Enfermagem no ambiente de Centro Cirúrgico e Licenciado pela Universidade Nove de Julho - SP. Mestrando em Educação com Especialidade em TICs pela Universidade Internacional Ibero-Americana - Porto Rico. Docente na Formação de Profissionais de Nível Médio Profissionalizante - Técnico em Enfermagem pelo Serviço Nacional de Aprendizagem Comercial -SENAC - São Paulo. E-mail: ferreiramagem@gmail.com.
} 
processo ensino - aprendizagem. Abordaremos também os processos históricos no mundo educativo e as intervenções possíveis mediante a ação do tutor. Durante os apontamentos discorreremos sobre a importância da família, e o diálogo como forma de negociação para a resolução de eventuais conflitos emergentes tendo vertente as tecnologias digitais e ações que melhorem o desempenho acadêmico dos tutoriados. Abarcaremos com fatores que possam vir a impossibilitar ou intervir no processo educativo e propor soluções que contribua com o desenvolvimento psicossocial dos estudantes.

Talvez o significado mais marcante de nosso trabalho e de maior alcance futuro seja simplesmente nosso modo de ser e agir enquanto equipe. Criar um ambiente onde o poder é compartilhado, onde os indivíduos são fortalecidos, onde os grupos são vistos como dignos de confiança e competentes para enfrentar os problemas - tudo isto é inaudito na vida comum. Nossas escolas, nosso governo, nossos negócios estão permeados da visão de que nem o indivíduo nem o grupo são dignos de confiança. Deve existir poder sobre eles, poder para controlar. $\mathrm{O}$ sistema hierárquico é inerente a toda a nossa cultura. (ROGERS, 1992, citado por BACICH et. al, 2015 p. 66).

\section{Marco Conceitual da ação tutorial}

A ação tutorial, ação é o ato de agir sobre alguém, partindo dessa premissa podemos

dizer que é algo a ser planejado e organizado com a finalidade de agir de maneira positiva enquanto tutoria nos aporta para proteção, conselheira e confiança alguém que irá contribuir de forma humanizada para a qualidade aprendizagem. Para Arraiz e Isús "a ação tutorial como atividade pretende reforçar as atuações tanto de professores pais e alunos como de todo pessoa e que incide direta ou indiretamente na educação”. Afirmamos assim a importância do ato relacional de colaboração e cooperação tanto na ação programada como através da observação e o diálogo, ação fundamental nesse processo com os profissionais e os indivíduos e que transitam no âmbito escolar de um centro ou na universidade, associada a um currículo escolar. Como toda ação o profissional ou tutor deverá preocupar-se com a inclusão dentro dos meios escolares DUA - Desenho Universal de Aprendizagem e tem como especificidades atender a todos auxiliando - os no desenvolvimento de seu processo de aprendizagem, permitindo assim a formação integral do indivíduo tendo como apoiador desse processo um tutor ou um grupo de tutores. Podemos afirmar que a partir deste elo haverá contribuição para a formação integral do estudante e o também no seu processo de aprendizagem significativa utilizando a tecnologia digital como ferramenta agregadora no processo educativo. 


\section{I.I Ação tutorial até os dias atuais}

A ação tutorial como conceito de atender as características diferenciais frente às ações pedagógicas no mundo da educação começou em 1592 com Comenius, Rosseau, Pestalozi, Dewey, Manjon, Montessori, Decroly, Vygotsky, Piaget até os dias atuais todos com mesmo propósito a aproximação do estudante com o seu tutor ou curas $^{4}$ com o crescimento da Aristocracia a relação do poder queriam que seus filhas e filhos recebessem ensinamentos religiosos e que aprendessem a ler e escrever e conhecessem a lei. De acordo com Expósito López (2014 p.28) “como são o conhecimento de si mesmo a necessidade de determinar as aptidões dos indivíduos e a importância da escola de atividade em função dos interesses dos indivíduos”. Ficando explicitada a relação do poder em relação à educação nos levando a repensarmos a condição humana desde a era aristocracia. Neste momento surge a figura de Platão, Aristóteles e Sócrates como referência para o pensamento critico e reflexivo sobre a ação do educador frente à aprendizagem, pois a figura do tutor no processo educativo estava a serviço da elite aristocrata.

Ver a aprendizagem como algo ligado à história de vida é entender que ela está situada em um contexto, e que também tem história - tanto em termos de histórias de vida dos indivíduos e histórias e trajetórias das instituições que oferecem oportunidades formais de aprendizagem como de histórias de comunidades e situações em que a aprendizagem informal se desenvolve (GOODSON, 2007, citado por BACICH, 2015 p. 250).

\subsection{Impactos da Era Industrial e Contemporânea na Ação Tutorial}

Com advento da Revolução Industrial no final do século XIX início do século XX, a sociedade começa a tomar novos rumos, surgindo à migração intercultural em direção aos Estados Unidos, provocando a mudança da organização social e a mudança no papel educativo familiar. Com a mudança abrupta e o inesperado crescimento industrial, houve a necessidade de aproximação do mundo do trabalho com a escola, levando a pensar num currículo que adaptasse a essa nova era, e profissionais aptos para exercer essa nova função, surgindo então à orientação vocacional. Segundo Alli (2014) "implementar um plano de estudos de orientação vocacional, mediante a concepção de um programa de aproximação e exploração dos ofícios, com acompanhamento, práticas profissionais sobre a

\footnotetext{
${ }_{4}$ Curas: Instituído para cuidar de uma pessoa incapaz. O curador sempre será ligado a alguém em razão de causa psicológica, seja de absoluta ou relativa.
} 
prática dos estudantes". Para Libâneo (2006) “a transformação da escola depende da transformação da sociedade, pois a forma de organização do sistema socioeconômico interfere no trabalho escolar e no rendimento dos alunos". Observamos que a mudança ocorre num momento de grandes impactos na sociedade, assim associamos o momento pandêmico que o mundo globalizado passa $e$ as transformações educacionais, principalmente as relacionadas com as tecnologias digitais, evitando que os alunos não sofram com os impactos negativos, proporcionando a ação tutorial, rever os seus objetivos e estratégias .

Segundo a OECDs (2020),

Escolaridade interrompida, escolaridade repensada: como a pandemia de Covid-ı9 está mudando a educação das crianças. [...] Um componente importante da implementação da estratégia de continuidade foi o desenvolvimento profissional para professores, principalmente usando plataformas online que permitiu que eles se comunicassem com seus pares.

Os próprios alunos devem ser vistos como agentes de sua própria aprendizagem, e seus papéis na aprendizagem devem ser reinventados para alavancar e cultivar sua agência, propósito, autodireção e aprendizagem independente. Diante do fato exposto são mudanças que são expostos a diversidade e os fatores internos e externos que pairam sobre a educação e novos modelos de ação tutorial surgem com a finalidade de contemplar as adversidades surgidas no mundo. Landau (2016 p.17) afirma que: "as tentativas de sintetizar as práticas educativas são simplesmente isso, tentativas, aproximações a uma realidade que é bem mais contraditória que as intenções dos documentos, regulamentado e as vontades dos agentes dos sistemas educativos”. Portanto podemos dizer que duas dimensões se cruzam no final desse processo da ação tutorial e a Orientação Educativa, a ação tutorial é acolhedora a serviço do estudante e da família "a orientação educativa une ao âmbito trabalhista tendo duas modalidades: a educativa e a profissional, onde a AT, entra entre esses dois eixos com a função de orientar e educar com o mesmo objetivo de acolhimento. Vislumbrar a aprendizagem como algo ligado à história de vida é entender que ela está situada em um contexto, e que também tem história - tanto em termos de histórias de vida dos indivíduos e histórias e trajetórias das instituições que oferecem

${ }^{5}$ OECD- Organização para a Cooperação e Desenvolvimento Econômico 
oportunidades formais de aprendizagem como de histórias de comunidades e situações em que a aprendizagem informal se desenvolve” (GOODSON, 2007, p. 250). Portanto o contexto histórico nos permite aprofundarmos no conhecimento em favor de novas formas estratégicas para chegar à formação dos estudantes.

\subsection{Estrutura da Ação Tutorial Em Sala de Aula}

A ação tutorial em sala de aula tem um papel importante para o estudante, pois favorece ações pensadas para as diferentes realidades que possamos ter em nas classes heterogêneas proporcionando a ação docente no âmbito da AT. Para Gimeno Sacristán (1999) citado por Castro (2020) "ainda apresenta o conceito de prática pedagógica como àquela que acontece nas salas de aula e não pode ser tomada de modo isolado ou em uma perspectiva de prática cultural autônoma e solitária”. Mas com ação tutorial o docente ajudará criança, adolescentes e jovens a construir uma imagem positiva de si mesmo, observará o emocional de seus alunos, contribuindo assim com a ampliação do seu cognitivo e emocional motivando para o desenvolvimento do seu processo educativo e o

levando o Aprender a Aprender, podemos observar o trabalho diário sendo desenvolvido através das modalidades denominadas de: Tutoria individual, Tutoria á distância, grupo e classes, grupos pequenos entre iguais e grupos fiscalizadores cada um com uma função. Faremos uma breve descrição de cada das modalidades apresentadas:

a) Tutoria individual: Trata-se da atenção individualizada um desenvolvimento de uma relação direta entre aluno/tutor;

b) Tutoria á distância: Grupos flexíveis, favorecidos pelas Tics, podem ser desenvolvidos pela plataforma Moodle, e-mail ou skype, o trabalho pode ser realizado tanto em grupo, pares ou individual;

c) Grupo classe: Esta modalidade é voltada para questões de convivência, são ações programadas com a finalidade do diálogo para evitar que conflitos pré-existentes, pode ser realizada através de projeto específicos;

d) Grupos pequenos: Parecida com a modalidade grupo classe, utilizado para resolver problema relacionado a rendimento acadêmico e realizar trabalho em grupo; 
e) Entre iguais: Modalidade de tutoria baseada na aprendizagem, como o trabalho na aula, com atividades cooperativas, a aprendizagem baseada em problemas;

f) Grupos focalizados: Modalidade de tutoria voltada para estudantes com problemas psicossociais, trabalha com temas específicos como alcoolismo, violência doméstica, orientação sexual, gênero entre outras. Nesta modalidade necessita que os tutores trabalhem em grupos ou pares com auxílio da orientação escolar da instituição e que o diálogo e a observação seja a chave para a solução da problemática apresentada.

\subsection{Desenvolvimento das modalidades de acordo com os níveis escolares}

As modalidades da AT, atua em quatro níveis educacionais e cada uma destinada a um grupo específico com um planejamento que atendam os estudantes. Abaixo relacionaremos a atuação desde a pré- escola ao universitário.

- $\quad$ Pré-escola

Modalidade-Tutoria individual e Pequeno grupo

- $\quad$ Fundamental I

Modalidade: Tutoria Individual, Pequeno grupo, Entre colegas e Grupo em classes.

- $\quad$ Fundamental II

Modalidade: Tutoria Individual, Pequeno grupo, Entre colegas e Grupo classe e Grupo focalizado.

- $\quad$ Ensino Médio

Modalidade: Tutoria Individual, Pequeno grupo, Entre colegas e Grupo classe e Grupo focalizado e A distância.

- Universitário

Modalidade: Tutoria Individual, Pequeno grupo, Entre colegas e Grupo classe e Grupo focalizado e A distância.

Ressaltamos a importância do olhar de observador do tutor, porque o modelo de ação Tutorial dependerá da realidade educativa onde a ação será inserida. Salientamos de 
os objetivos de: Para quem? Onde? Como deveria ser realizada? Dependerá de realidade para realidade onde o contexto educativo acontece e as intervenções propostas na ação Tutoria.

Para Castello e Monereo (200o), "cada uma dessas modalidades da organização do ensino de estratégias pode ter diferentes vantagens e limitações e, de fato, e apesar de que na literatura e na pesquisa se advogue pelas duas últimas, parece que, na prática, todas elas coexistem com diferentes graus de êxito”. Premissas a tutoria, tem como objetivo orientar o estudante ou grupo de estudantes em cooperação e colaboração com ajuda do professor. Partindo assim para o seu desenvolvimento integral dos estudantes. Portanto orientar é auxiliar o estudante a se encontrar consigo, para através da motivação o faça prosseguir e se ver como ser humano capaz de refletir criticamente sobre o seu papel na sociedade. Assim podemos afirmar que tutoria é essencial dentro do sistema educativo e deve colaborar como proposta viável e consistente de forma global.

\subsection{Intervenção da ação Tutorial}

No sistema educativo a intervenção tutorial precisa abarcar por um caminho que a família, a equipe gestora e professores devam ser um grupo com a principal função, o diálogo entre pares ou grupos para que de fato a intervenção contribua para a negociação com a finalidade de ajudar os estudantes na sua vida acadêmica, evitando conflitos e mal desempenho acadêmico. Para que isso aconteça, é necessário que a interação e a observação se façam instrumentos fundamentais e, através delas, as instituições escolares aproximam o contexto familiar dos estudantes. Nesta perspectiva, o tutor se aproxima da família e acompanhará o processo de formação dos filhos das mesmas, intencionalmente oportunizando os pais aproximarem do progresso social, familiar de seus filhos passando os integrantes desta ação a se relacionarem conjuntamente proporcionando uma relação harmônica entre os envolvidos permitindo uma reflexão de suas ações. Diante do exposto descrevemos os níveis de intervenções da escola á universidade que são definidos como: Funcional, Organizacional e Estrutural.

a) Nível I - Funcional, refere-se à individualidade de cada estudante ou seu seja o seu cotidiano, onde a ação tutorial é individual ou em pequenos grupos, 
onde o tutor é a pessoa que irá ajudá-lo diante da sua caminhada acadêmica. Esse nível precisa de um atendimento individual e um contato com os estudantes e também com os professores e logicamente a comunicação com a família.

b) Nível 2 - Organizacional ocorre-se dentro do departamento de orientação.

Onde as ações são planejadas e implementadas, onde a orientação sobressai melhor a partir das escolas secundárias, e contam também com equipes multidisciplinares (psicólogos, professores, pedagogos, assistente social, médico, psicopedagogos entre outros) neste nível exigem uma atenção especial aos tutoriados.

c) Nível 3 - Neste nível entra as ações definidas pelo ministério, responsável pela organização geral do país favorecendo a ação tutorial através da estrutura oferecidas para que a qualidade da educação aconteça através de ações que tenha como apoio uma base sólida.

\subsection{Perfil do professor/tutor}

O perfil do professor tutor é muito relevante independente da modalidade de ensino, ele deve fazer a ponte entre o aluno e o objeto de conhecimento numa perspectiva construtiva, desafiadora e prazerosa. A prática educativa do tutor deve guiar o estudante a partir do diálogo para que o mesmo, elabore seu próprio conhecimento, pois essa ação tutorial implica algumas habilidades intra e interpessoais.

Segundo Leal (2005, p.3):

Defendemos uma concepção de que o tutor seria aquele que, problematizando o conhecimento crie estratégias em que o aluno veja o mundo e a si mesmo e vislumbre os riscos, as incertezas, a temporalidade humana, as vantagens da tecnologia, do conhecimento e o encantamento do aprender.

Além de proporcionar um discurso aberto para reconstruir novos significados, o tutor perceberá as mudanças paradigmáticas voltadas para novas competências tanto para tutor quanto para estudante. As novas competências buscam romper com o conteúdo fragmentado e linear para dar lugar ao conhecimento transdisciplinar numa construção coletiva que instiga a participação de todos, fomenta o pensamento crítico e reflexivo. 
No contexto da modalidade EAD o papel do tutor vai muito além da visão técnica porque precisa mediar a aprendizagem articulando relação entre teoria e prática. Sabendo que didática é a arte de ensinar o tutor necessita de uma formação acadêmica que contemple conhecimentos didáticos pedagógicos. Para Candau (1983) a didática deve abranger as dimensões humanas, político-social e técnica enquanto para Pischetola (202I) é preciso ter cuidado para que as tecnologias digitais não ocupem o lugar da técnica nos dias atuais favorecendo o tecnicismo.

Ambos, tutor presencial e tutor de EAD podem manter a aproximação constante com os estudantes, basta pensar em estratégias inovadoras que possibilitem interação. Existem algumas variáveis que devem ser analisadas pelos tutores, uma é o perfil do aluno e outra é o estado psicológico do mesmo para iniciar um bom relacionamento entre professor e estudante, nunca esquecendo que o aluno deve estar no centro do processo de aprendizagem como protagonista.

Um dos maiores desafios para o tutor é estimular a participação dos estudantes quando falamos de tutoria EAD, intervir, orientar e dar feedback deve ser uma tarefa contínua, na sala de aula presencial a complexidade do processo educacional não é diferente principalmente no que tange ao cenário comunicacional o qual nos encontramos,a análise é essencial para os estudantes ao selecionar conteúdos e estratégias de ensino.

A tutoria em pares ou em grupos também exige um olhar mais atento do tutor, principalmente para observar a caminhada dos alunos e realizar as intervenções necessárias para que a parceria seja produtiva e as orientações devem contribuir para um efetivo compartilhamento de saberes. Para implementar uma boa estratégia de tutoria em pares ou em grupos é importante planejar uma PAT prevendo os objetivos de aprendizagem e as respectivas metodologias para alcançar o propósito desejado.

A parceria proporciona o colega ensinar o outro, sendo uma experiência que tende a dar bons resultados, despertando a troca entre iguais (no sentido de idade cronológica) facilita a compreensão entre ambos, visto que possuem a linguagem semelhante justamente por não ser especialista e além disso, alguns estudos já comprovam que a aprendizagem flui muito mais quando estamos ensinando. 
Considera-se que ensinar permite aprender, porque a aprendizagem se realiza através da interação: "O "tutor" aprende ensinando ao seu colega tutorado, porque implica uma preparação prévia dos conteúdos, atividades a desenvolver a co-construção de conhecimentos graças a mediação, divergência de opiniões e ideias, e consenso de respostas. FUNIBER (2020, p. 6I)

A concepção pedagógica do tutor deve ter uma linha de pensamento humanista que pressupõe o respeito a diversidade muito presente nos ambientes educacionais, sendo presencial ou virtual, a heterogeneidade deve ser vista como uma oportunidade de enriquecimento educacional, a ação tutorial pode contribuir muito para ajustar as necessidades específicas de cada estudante numa abordagem acolhedora de amparo e cuidado, podendo assim potencializar e qualificar a prática educativa da tutoria.

\section{CONSIDERAÇÕES FINAIS}

As considerações feitas no artigo "Perspectivas da ação Tutorial no Espaço Educativo na era Contemporânea" tem como foco principal discorrer sobre a importância da ação tutorial na aproximação da família, Instituição e professor/tutor, na contribuição do desenvolvimento socioemocional dos estudantes e na construção de novos saberes. Como principal aliado nesta construção temos as tecnologias como forma de inclusão em todos as modalidades do sistema educativo, assim como a sua trajetória até os dias atuais, culminando com o perfil do Professor/tutor. Na eficiência do desenvolvimento integral dos estudantes. A transformação e construção de novos conhecimentos, permitindo a aquisição de competências a fim de uma convivência harmoniosa, e de respeito com o seu semelhante. Ao longo da pesquisa elencamos como as intervenções favorecem as aproximações e aprendizagens significativas, e os impactos do momento pandêmico o qual estamos vivenciando e os causas e efeitos no sistema educativo e as possibilidades de inclusão para que obtenham igualdade e equidade na aprendizagem e que as habilidades e competências sejam de fato aprendidas.

Percorremos sobre a importância do tutor/professor tanto na modalidade presencial como na modalidade $\mathrm{EAD}$, ressaltando a importância da observação e o diálogo nas intervenções pedagógicas individuais em pares e em grupo na ação tutorial. Portanto a mudança da concepção do professor/tutor frente a era contemporânea criam vertentes e 
estímulos nas práticas de cooperação e colaboração, com tutores que transmitam confiança e tenha a disponibilidade para a escuta ativa uma das competências exigidas para o Professor/Tutor no século XXI.

\section{REFERÊNCIAS}

BACICH, Lilian; TANZI, Adolfo Neto; TREVISANI, Fernando de melo. Ensino híbrido: personalização e tecnologia na educação [recurso eletrônico] Porto Alegre: Penso, 2015. e-PUB.

BARROS, Leal da Silveira, R. L. (2005). A importância do Tutor no processo de aprendizagem a distância. Revista Iberoamericana De Educación, 36(3), I-6. https://doi.org/10.35362/rie3632815

CANDAU, VM. A Didática e a Formação de Educadores - Da exaltação à negação: a busca da relevância. In: CANDAU, V, M. (org) A didática em questão. Petrópolis, RJ: Vozes, 1983.

CASTro, TC; GAlVÃO, TF; LUNA, AVA; GAlVÃO, NCSS (2020). Educação Científica, Inclusão e Diversidade. Cruz das Almas, BA: EDUFRB.

COLL. C; \& MONEREO, C. (2010). Educação e Aprendizagem no século 2r: Novas ferramentas, novos cenários, novas finalidades. COLL. C; \& MONEREO, C. Educação virtual: Aprender e ensinar com as tecnologias da educação e da comunicação. Porto Alegre: Artmed, $15-46$.

FUNIBER. A Ação Tutorial no Sistema Educativo: Técnica e instrumentos para a ação tutorial. 2020. Espanha

LANDAU, M. (2016) Las tutorias em la educacion secundaria Políticas nacionales provinciales y práticas Ininstitucionales. Ministerio de educación Deportes de la Argentina. Direcion Nacional de Informacion y Estatísticas Educativas. Disponível em hhtp://.bnm.me.gov.ar/gigar/documentos/ELoo5554.pdf

LIBANÊO, José Carlos (2006). Didática. Cortez Editora, São Paulo/SP. 
LÓPEZ, Expósito J. (2004) La acción tutorial y en la educación actual. Barcelona; Editorial Síntesis

PISCHETOLA, Magda; MIRANDA, Thédiga, Lyana. A sala de Aula como Ecossistema: Tecnologias, Complexidade e Novos Olhares para a Educação. Petrópolis: Vozes. Rio de Janeiro: Editora PUC, 2021.

REIMERS, Fernando; SCHLEICHER, Andreas. Schooling disrupted, schooling rethought: How the Covid - 19 pandemic is changing education. Preliminary version [Recurso Eletrônico], Organisation for Economic Co-operation and Development (OECD), 2020. 